\title{
O USO DOS JOGOS PARA ANÁLISE DE AÇÕES DE (IN) DISCIPLINA
}

Andressa Carolina Scandelai Parra, Camila Fernanda Dias Pavaneli, Francine Guerra de Luna, leda Alves Lulio, Kelly Regina Conde, Luciana Ap. Nogueira, Stephanie Lee Basile Barboza Caseiro.

Universidade Estadual Paulista - UNESP, Curso de Pós-Graduação em Ensino e Processos Formativos, São José do Rio Preto, SP. E-mail: andressa_parra3@hotmail.com.

\section{RESUMO}

O tema indisciplina/disciplina é considerado fundamental para a aprendizagem escolar e a vida em geral. Essa questão sempre esteve presente nas oficinas do Laboratório de Psicopedagogia (LaPp). Diante disso, a presente pesquisa teve como objetivo identificar ações das criançasem oficinas de jogos.A metodologia constou da observação de três crianças, com 10 e 11 anos de idade. Caracterizamos do ponto de vista conceitual aspectos de disciplina e indisciplina. Como resultados, verificamos que as atitudes mais observadas foram de desrespeito e a menos observada de trapaça; em relação à frequência das ações de indisciplina, pudemos verificar que ao final da oficina, estas ações foram reduzidas drasticamente.Concluímos que as oficinas de jogos constituem um espaço no qual, além de as crianças ampliarem seus recursos cognitivos,são desenvolvidas atitudes favoráveis à aprendizagem, que requerem, dentre outros, o desenvolvimento de ações de disciplina.

Palavras-Chave: Disciplina; Indisciplina; Jogos; Construtivismo; Piaget.

\section{THE USE OF GAMES TO ANALYZE ACTIONS OF (IN) DISCIPLINE}

\begin{abstract}
The indiscipline/discipline theme is considered fundamental for school learning and life in general. Thisissuewasalwayspresent in theworkshops oftheLaPp - Laboratório de Psicologia. Therefore, the present research aimed to identify children's actions in games workshops. The methodology consisted of the observation of three children, with 10/11 years of age. We characterize aspects of discipline and indiscipline from the conceptual point of view. As results, we verified that the most observed attitudes were of disrespect and the less observed were of cheating; In relation to the frequency of indiscipline actions, we could verify that at the end of the workshop, these actions were drastically reduced. We conclude that playgroups constitute a space in which, in addition to children expanding their cognitive resources, attitudes that favor learning are developed, which require, among others, the development of discipline actions.

Keywords: Discipline; Indiscipline; Games; Constructivism; Piaget.
\end{abstract}




\section{INTRODUÇÃO}

A disciplina/indisciplina está presente em contextos escolares, do trabalho e da vida em geral e, por sua complexidade, pode ser analisada sob muitos aspectos, recortes teóricos ou empíricos. Uma maneira de compreender e lidar com este tema é por meio de oficinas que envolvam reflexões e intervenções de profissionais competentes nas ações das crianças.

A construção da disciplina (como qualquer construção) é tecida em uma rede de relações. "Trata-se, portanto de uma realização complexa que compreende muitos elementos, que pode ser estruturada e desenvolvida de muitos modos" (MACEDO, 2005b, p.151). Assim, a construção da disciplina relacionada com autodisciplina, supõe autonomia, supõe responsabilidade por suas ações e consequências, supõe autodeterminação.

Escolhemos esse contexto também porque inferimos que a dimensão lúdica presente nos jogos e outras atividades propostas nas oficinas despertam o interesse das crianças para aprender em meio a regras. $O$ modo de as crianças se relacionarem com as regras e com os colegas são pontos de referência para observarmos e qualificarmos uma conduta como de disciplina ou indisciplina.

A hipótese inicial de inserção destes alunos no projeto de oficinas de jogos foi pensada em proporcionar-lhes benefícios, promovendo o desenvolvimento de aspectos cognitivos e favorecendo a construção de algumas competências e de atitudes mais favoráveis à aprendizagem. A partir daí, traça alguns objetivos específicos para verificar essa hipótese. Partindo das queixas relatadas (dificuldades escolares), buscou interpretá-las à luz da questão do fracasso escolar.

Nosso estudo teve como objetivo identificar ações de indisciplina em crianças em situação de oficinas de jogos. Caracterizamos do ponto de vista conceitual os aspectos de disciplina (atenção/concentração, respeito e persistência) e indisciplina (desatenção/dispersão, desrespeito, trapaça e desistência) numa perspectiva teórica (PIAGET, 1994; MACEDO, 1996; LA TAILLE, 1996).

\section{METODOLOGIA}

A metodologia consistiu na observação das ações das crianças em oficinas de jogos. Escolhemos esse contexto pelo fato de que inferimos que a dimensão lúdica presente nos jogos e outras atividades propostas nas oficinas despertam o interesse das crianças para aprender em meio a regras. Este trabalho foi submetido na Plataforma Brasil, com CAAE 68201217.4.000.5466.

\section{PARTICIPANTES}

As três crianças escolhidas como sujeitos desta pesquisa, são oriundas de famílias com baixa renda e têm um ou ambos os progenitores dependentes químicos. Elas frequentavam quinto ano do Ensino Fundamental I, de uma escola pública da cidade de São Paulo, mas estudavam em salas de aula diferentes. Duas tinham dez (C2 e C3) e outra (C1) onzeanos de idade. Segundo a diretora da ONG, as crianças tinham queixas de insucesso na aprendizagem escolar.Elasforam escolhidas ao longo das cinco primeiras oficinas (dentre as doze crianças que participavam das oficinas) por apresentarem maior número de comportamentos de indisciplina observados. Os conteúdos dos registros de observação foram sistematizados e analisados, de acordo com a proposição de Bardin (1977/1995).

\section{LOCAL}

O local de investigação da presente pesquisa foi um Laboratório de Psicopedagogia da Universidade de São Paulo. Desde a criação deste Laboratório em1988, muitas oficinas de jogos foram oferecidas à crianças, adolescentes, adultos (professores, profissionais) e idosos, com o objetivo de desenvolver habilidades cognitivas, afetivas e sociais da população atendida.E realizar estudos das relações entre o jogo, os profissionais do laboratório, as crianças ou as habilidades 
adquiridas. Além das oficinas de jogos, os profissionais deste laboratório ministraram diversos minicursos, grupos de estudos e formação a professores e profissionais interessados, sempre com base na epistemologia genética de Piaget.

As oficinas para crianças contam com um grupo composto, em média, de doze sujeitos. Funcionam uma vez por semana, durante uma hora e meia, o que totaliza 12 a 15 encontros por semestre, são dirigidas, normalmente, por uma dupla ou trio, formados por uma técnica ou por um monitor (aluno de pós-graduação), um ou dois auxiliares (aluno de graduação) e supervisionadas por um coordenador.

\section{PROCEDIMENTOS}

Para realizar esta pesquisa, utilizamos os registros de observação escritos e produzidos no decorrer do processo de oficinas de jogos. Ao longo do trabalho nas oficinas (três semestres) regularmente, registramos ações indicadoras de indisciplina das crianças. Não tínhamos um foco específico sobre o registro de suas atitudes em relação às tarefas, professores, colegas, etc. Nosso olhar era voltado às crianças em todo o processo da oficina e, quando percebíamos uma ação de indisciplina, a registrávamos. Dividimos as ações observadas em categorias: dispersão/desatenção, desrespeito (às regras do jogo ou atividade proposta, aos colegas, às regras da oficina), desistência e trapaça. As ações de disciplina (ações positivas) não foram foco de nossa observação nas crianças, pois acreditamos que elas seriam um ponto de chegada. Comentamos sobre as categorias de disciplina: atenção/concentração, respeito e persistência na Discussão desse trabalho.

\section{RESULTADOS}

A apresentação dos resultados destacaos registros de observação das três crianças escolhidas como sujeitos (C1, C2 e C3), ilustrando ações de indisciplina em situação de oficina de jogos.As atividades realizadas nas oficinasseguem quatro movimentos: a lista de presença, uma atividade inicial, a atividade principal (sendo jogo ou outras atividades gráficas) e o momento de reflexão.

Foram reunidas observações referentesàs ações indicadoras de indisciplina nos seguintes momentos considerados significativos: jogos (atividades propostas) e reflexão. Para análise da evolução das ações das crianças, apresentamos tabelascom a frequência das ações de indisciplina de cada criança ao longo dos 3 semestres observados.

Os registros de observação demonstraram as ações de indisciplina dos sujeitos nas categorias de: desatenção/dispersão (mostram sinais de desinteresse ou agitação, focando-se em outras atividades que não são a que está sendo proposta), desistência (recusa à realização ou abandono da atividade), desrespeito aos colegas (brigas, provocações e interrupções), desrespeito às regras da oficina (não participar ou prejudicar o desenvolvimento desta), desrespeito às regras da atividade proposta e trapaça (burlar as regras em benefício próprio). Alguns registrospodem encontrar-se em duas ou mais categorias, porém a ação destacada se refere à categoria em que ela está inserida.

Apresentamos a seguir as tabelas da frequência de ações de indisciplina observadas ao longo dos 3 semestres da oficinaem C1, C2 e C3. Essas tabelas têm como objetivo mostrar a evolução apresentada nas ações de cada uma das crianças ao longo das oficinas. 
Tabela 1. Ações de indisciplina de $\mathrm{C} 1$ ao longo das oficinas

\begin{tabular}{|l|c|c|c|c|}
\hline C1 & 10 Semestre & 2o Semestre & 3o Semestre & TOTAL \\
\hline Dispersão & 9 & 6 & 2 & 17 \\
\hline Desrespeito & 12 & 11 & 4 & 27 \\
\hline Desistência & 6 & 4 & 0 & 10 \\
\hline Trapaça & 0 & 1 & 0 & 1 \\
\hline TOTAL & 27 & 22 & 6 & 55 \\
\hline
\end{tabular}

Tabela 2. Ações de indisciplina de $\mathrm{C} 2$ ao longo das oficinas

\begin{tabular}{|l|c|c|c|c|}
\hline \multicolumn{1}{|c|}{ C2 } & 10 Semestre & 20 Semestre & 30 Semestre & TOTAL \\
\hline Dispersão & 2 & 5 & 4 & 11 \\
\hline Desrespeito & 15 & 27 & 2 & 44 \\
\hline Desistência & 0 & 4 & 0 & 5 \\
\hline Trapaça & 2 & 3 & 0 & 5 \\
\hline TOTAL & 19 & 39 & 6 & 64 \\
\hline
\end{tabular}

Tabela 3. Ações de indisciplina de C3 ao longo das oficinas

\begin{tabular}{|l|c|c|c|c|}
\hline C3 & 10 Semestre & 20 Semestre & 3o Semestre & TOTAL \\
\hline Dispersão & 4 & 16 & 2 & 22 \\
\hline Desrespeito & 8 & 28 & 3 & 39 \\
\hline Desistência & 3 & 4 & 0 & 7 \\
\hline Trapaça & 0 & 1 & 0 & 1 \\
\hline \multicolumn{1}{|c|}{ TOTA } & 15 & 49 & 5 & 69 \\
L & & & & \\
\hline
\end{tabular}

\section{DISCUSSÃO}

Depreende-se que falar sobre indisciplina é falar sobre disciplina. Visto que "in" é prefixo de negação, neste caso, ele nega o conceito de disciplina. Ou seja, as ações de indisciplina são contrárias às de disciplina. Portanto, vemos que os jogos são excelentes meios para se observar esse prejuízo, de modo imediato e claro.

Uma das funções mais importantes do jogo de regras, segundo Piaget (1932/1994), é exigir de seus participantes o respeito mútuo. De fato, respeitar o colega implica, por exemplo, manterse quieto, em silêncio, enquanto ele faz sua jogada. Caso a criança desrespeite o colega, gritando na vez dele, pegar as varetas, por exemplo, o jogo perde a veracidade, porque esse desrespeito é considerado trapaça: "enganar usando de dissimulação".

Como resultado da frequência das ações de indisciplina de cada criança, verificamos que dois dos sujeitos observados (C2 e C3) agem com relativa indisciplina no primeiro semestre, aumentam as ações de indisciplina no segundo semestre e reduzem no terceiro semestre. Percebemos que o sujeito (C1) praticamente mantém a mesma quantidade de ações indisciplinadas no primeiro e segundo semestre, mas também as reduz drasticamente no terceiro semestre. Esse resultado mostra que as crianças diminuem seus comportamentos de indisciplina ao longo das oficinas.

A atitude mais observada nos três sujeitos foi de desrespeito e a menos observada de trapaça. C1 praticou 24,55\% (27 ações) das ações de desrespeito, seguido de C3 que realizou $35,45 \%$ (39 ações) e de C2 que praticou 40\% (44 ações) das ações de desrespeito.

No terceiro semestre, as crianças estão mais familiarizadas com o sistema de regras e, de uma maneira geral, consideramos que elas passaram a atribuir valor ao fato de triunfarem nas tarefas propostas. Desta forma, agem com menos indisciplina porque "querem" ser mais 
disciplinadas, ou seja, têm mais força de vontade para superar os desafios das tarefas. Parece que agora a disciplina é valorizada como meio para se alcançar uma determinada meta.

\section{CONCLUSÃO}

A presente pesquisa teve por objetivo identificar as ações das crianças em oficina de jogos. Assim, podemos concluir que as ações mais observadas foram de desrespeito; em relação à frequência das ações de indisciplina, pudemos verificar que ao final da oficina, estas ações foram reduzidas drasticamente. Vale destacar também que as ações menos observadas na oficina foi a trapaça. Além disso, entendemos que as oficinas constituíram em um espaço no qual, além de as crianças ampliarem seus recursos cognitivos, foram desenvolvidas atitudes favoráveis à aprendizagem: o que julgamos ter podido ilustrar com nossa pesquisa, enfocando, dentre estas atitudes, a construção de ações de disciplina. A estrutura das oficinas e os instrumentos (jogos e atividades gráficas) favorecem atitudes de disciplina. Vimos que essas atitudes são conquistadas pouco a pouco e diversos são os fatores que contribuem para essas ações: a estrutura organizadora das oficinas, os instrumentos (jogo e outras atividades) lúdicos e desafiadores, as intervenções dos profissionais, dentre outros. Esses fatores contribuem para o desenvolvimento de autoconfiança nas crianças. Dessa forma, elas buscam melhorar seus desempenhos e expandir a si próprias (com valores positivos) porque querem isso, consequentemente agem com menos indisciplina (mais disciplina).

\section{REFERÊNCIAS}

BARDIN, L. Análise de conteúdo. Lisboa: Edições 70, 1977.

LA TAILLE, Y. De.- A indisciplina e o sentimento de vergonha. In: Aquino, J. (org) Indisciplina em sala de aula. São Paulo: Summus, 1996.

LUNA. F. G. de. A (in) disciplina em oficinas de jogos. 2008. 171f. Dissertação (Mestrado em Psicologia).Universidade de São Paulo, 2008.

MACEDO, L (Org.). Cinco estudos de educação moral. São Paulo: Casa do Psicólogo, 1996. 2005b.

.Ensaios pedagógicos: como construir uma escola para todos? Porto Alegre: Artmed,

PIAGET, J. (1932) O juízo moral na criança. Trad. de E. Leonardon. São Paulo, Summus, 1994. 